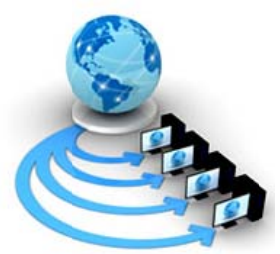

International Journal of Advanced Research in Computer Science

RESEARCH PAPER

\author{
Available Online at www.ijarcs.info
}

\title{
AN EMPIRICAL STUDY ON THE EXPERIENCES OF THE VISUALLY- IMPAIRED STUDENTS OF LOYOLA COLLEGE WITH ICT SUPPORT ON USING WWW.LOYOLACOLLEGE.EDU
}

\author{
J. Jerald Inico \\ Assistant Professor, \\ Department of Computer Science, \\ Loyola College, Chennai 600034, India.
}

\author{
Dr. T. Edwin Prabakaran \\ Associate Professor, \\ PG \& Research Department of Statistics, \\ Loyola College, Chennai 600034, India.
}

\begin{abstract}
The students with visual impairments want unique educational needs and a parent of these students expects interventions of information and communication technology(ICT) tools to meet the learning expectations of these students. It is observed that the field of education of visually impaired students was the first to develop a range of special education program options. In recent years, ICT is playing a vital role inthe development of educational curriculum and also in teaching learning process due to advancements in the area of IT and hardware. It supports the students to improve their knowledge and learning skills and enables them to most effectively compete with their peers in colleges and ultimately in society and hence the ICT based assistive tools are most widely used to support inclusive learning. This study reveals that knowledge of screen reader makes the visually-impaired students to access website and other information through desktop, laptop and mobile phones.
\end{abstract}

Keywords: Visually impaired students, Accessibility, Screen reader, Usability

\section{INTRODUCTION}

The right of education of the disabled people cannot be prevented by any reason. The disabled children, youngsters and adults are provided with equal education with the nondisabled people and in inclusive environments by taking the special conditions and differences into consideration. Inclusive education is the practice of integrating visually impaired students into regular classrooms. Differentiation becomes critically important in inclusive education in order to address the academic and social development of all students within the same classroom. However, there is a need to examine the practice of inclusive education in regard to visually impaired students' experiences. This qualitative study has explored the challenges of visually impaired students in higher education. The higher educational institutions have a great responsibility of delivering the necessary contents to their students through different media so that information is available at any time for accessing by means of web and internet which are one of the powerful ICT tools in providing education. Students with disabilities have the right to expect the same standard of education as their schoolmates and, in this view, they also have the right to access and use mainstream educational tools, including ICT based ones, which are generally referred to as "elearning tools"[1].

There are lots of evidence found in the literature that visually impaired cannot not use mouse and the screen that requires mouse operation is not possible to use for them. The image, photos and graphics are unusable which requires text descriptions or alternative text and longer explanations can be given in another page. They use a screen reader to listen to web pages which may skip navigational menus, long list of items, ASCII Art and other difficult items present in the web. They often use Tab key to move from a link to link and cannot follow the links out of context. The contents visually separable using frames are not seen all at once which requires appropriate frame titles to understand the text in the frames. The same problem exists in reading the contents present in the table format which may be presented with appropriate column and row headers to understand the contents in the table. The complex tables and graphs that are visually pleasing are unusable which requires the equivalent summaries and text descriptions. The image maps to locate content in a map are not supported in some of the screen readers that may require redundant text links to link the contents. The colors to classify the contents may not be useful which requires additional text to explain the differences. They use links to move from one page to another and can avoid scripts that may refer to content inside the same page [2].

The person with low vision also face challenges in recognizing the text in graphics for it does not enlarge or becomes pixilated when enlarged, it requires a limit or should eliminate text within graphics. They usually set their own fonts and background colors by offering text rather than text within graphics. The screen magnifiers reduce the usable window size which requires the relative units than absolute units.The people with Color-blindness cannot distinguish the difference between colors which requires the option to change the color or provide an explanation in the text itself [3]. However, the designers of a website have their own criteria to design.

\section{STATEMENT OF THE PROBLEM}

Through some significant research, human civilization got some radical inventions and ideas which enabled visually impaired people to become as competent as their peers, or more so. Since the time of Ancient Egypt, there has been an 
effort to make the lives of visually impaired people more meaningful. Information and Communication Technology (ICT) can be a tool to include visually impaired learners in education for all classrooms. But still the visually impaired people face problems with the usability and accessibility of ICT tools $[4,5]$.

As the administrative and academic information is made available on the website(www.loyolacollege.edu), it is required to provide in a convenient accessible format for every user. It enhances the access of information even by the visually impaired students without any hindrances if presented in a layout that supports easy accessibility and usability through personal computers and mobile phones.

\section{OBJECTIVE OF THE STUDY}

The main objective of the study is to assess the impact of accessibility of www.loyolacollege.edu for the benefit of Visually-impaired students of Loyola College, Chennai, India. The focus of the study is on determining the level of proficiency of using screen reader software to access a web site among visually-impaired students, to learn the relationship between the proficiency and the demographic nature, to know the relationship between the proficiency and the parents/ family background, to discover the difficulties of a screen reading software to read the contents in the web site, to understand the structure of web and the content distribution that makes discomfort, to find the discrepancy level of accessing the contents in the web site and to identify those factors that facilitates / hinders them in accessing the web site.

\section{METHODOLOGY OF THE STUDY}

This study was conducted in Loyola College due to its longtime experience in enrolling students with visual impairment and other physical disabilities. Data for this research were primarily collected from primary sources by distributing the questionnaire to 86visually impaired students studying in the undergraduate and few post graduate courses in Loyola College. These 86 students are specially trained in Loyola College through MRCDS(Model Resource Centre for Disability Services) for accessing the web sites and other ICT tools. As there is no such special centres in any other institution the data collection is restricted within Loyola College. The research design will utilize qualitative research design which focuses on the meanings people assign to the social phenomena experienced by them. There are several reasons for conducting qualitative research: One of the main reasons is the nature of the research problem and the other is the personal choice of the researcher itself.

Questionnaire was developed to collect the data from the students is based on Software Usability Measurement Inventory (SUMI) [6] which is a questionnaire method for analyzing products or prototypes in terms of usability and quality of use. It provides a standardized measurement of user satisfaction with software. The tool developed contains the questions that could answer the experience of the visually-impaired students in accessing the web content. The questionnaire was validated. The data collection steps include setting the boundaries for the study, collecting information through the questionnaire designed for this purpose, as well as establishing the protocol for recording information were followed as per the standard procedure.

\section{RESULTS OF THE STUDY}

The following table shows the number of visually impaired students admitted to various courses in Loyola College.

\begin{tabular}{|l|c|c|}
\hline \multicolumn{2}{|c|}{ Table 1: Visually-impaired Students Admission } \\
\hline \multicolumn{1}{|c|}{ Course } & Count & Percentage \\
\hline B.Com & 1 & $1 \%$ \\
\hline B.A Economics & 1 & $1 \%$ \\
\hline B.A English & 36 & $42 \%$ \\
\hline B.A History & 10 & $12 \%$ \\
\hline B.A Sociology & 1 & $1 \%$ \\
\hline B.A Tamil & 37 & $43 \%$ \\
\hline
\end{tabular}

Among 86 students in the list, there are 26 students completed their schooling in rural and 60 students in Urban. The study shows that $70 \%$ of the students are visually impaired by birth and 30\% lost their vision due to several reasons even after 5 years of age.

This study is mainly to answer the following questions relating to accessing of ICT tools by visually impaired students in Loyola College.

1. There is a relationship between the demography of the student and the use of screen readers for accessing the website. The Fisher's Exact Test for Count Data expressed p-Value as 0.0780622.This result reveals that students in urban area are getting more exposure than the students in the rural area in accessing website using screen readers.

2. There was no marked difference identified between the visually impaired students with respect to their parent educational qualification and occupation; however the educated parent play a small role in motivating and providing opportunities for their wards in using ICT tools. The data expresses that the students these selected students are given computer training in the elementary, high school, middle school and the college level to equip them to access ICT tools.

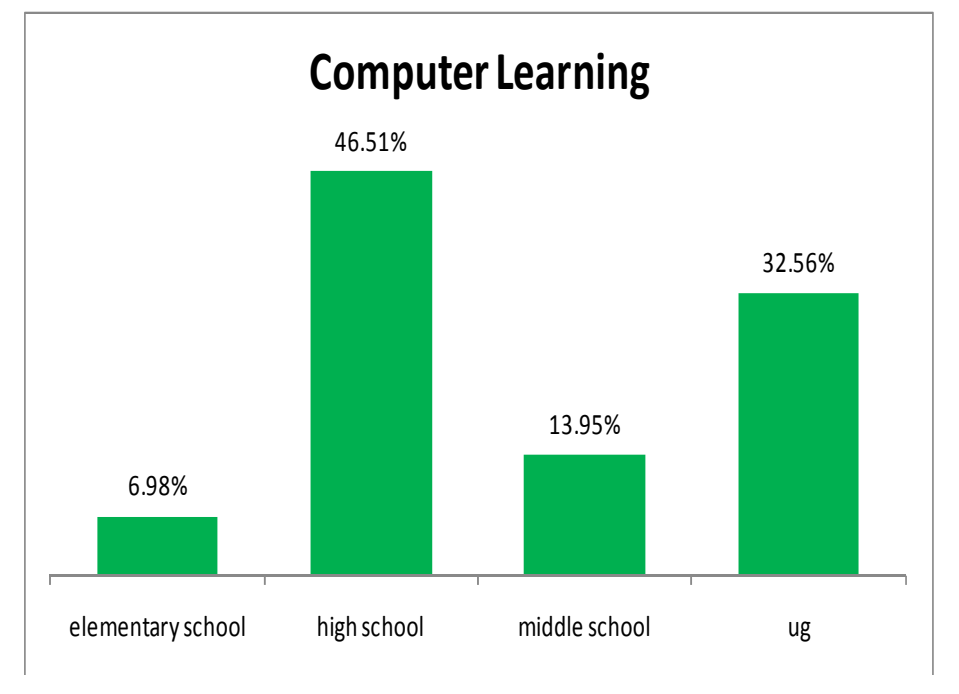

3. Table 2 indicates that $40 \%$ of the students in the sample are accepting that they are in the beginning stage of using screen reader, $46 \%$ of the students are trained to effectively use screen reader and hence this $86 \%$ are 
able to access the website www.loyolacollege.edu without any hindrances. Most of the students are comfortable with use of screen reader due to its features as represented in the diagram.

\begin{tabular}{|l|c|r|r|r|}
\hline \multicolumn{6}{|c|}{ Table 2: Usage of Screen reader for accessing website } \\
\hline $\begin{array}{c}\text { Users } \\
\text { Level }\end{array}$ & $\begin{array}{c}\text { Exper } \\
\text { t }\end{array}$ & $\begin{array}{c}\text { Advance } \\
\text { d }\end{array}$ & $\begin{array}{c}\text { Intermediat } \\
\text { e }\end{array}$ & $\begin{array}{c}\text { Novic } \\
\text { e }\end{array}$ \\
\hline Numbers & 17 & 23 & 34 & 12 \\
\hline $\begin{array}{l}\text { Percentag } \\
\text { e }\end{array}$ & $20 \%$ & $26 \%$ & $40 \%$ & $14 \%$ \\
\hline
\end{tabular}
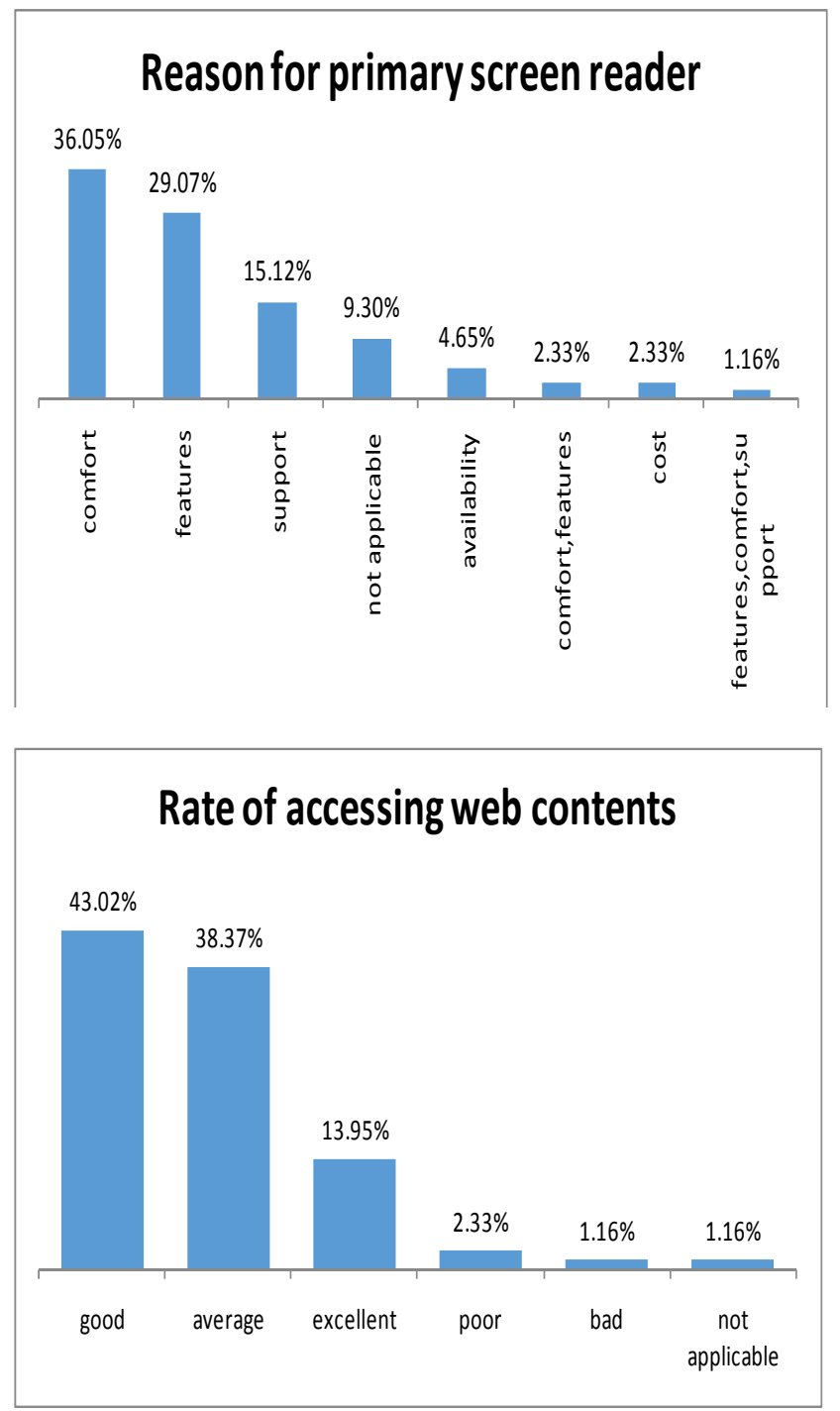

There are several other screen readers used by these students for accessing the websites.

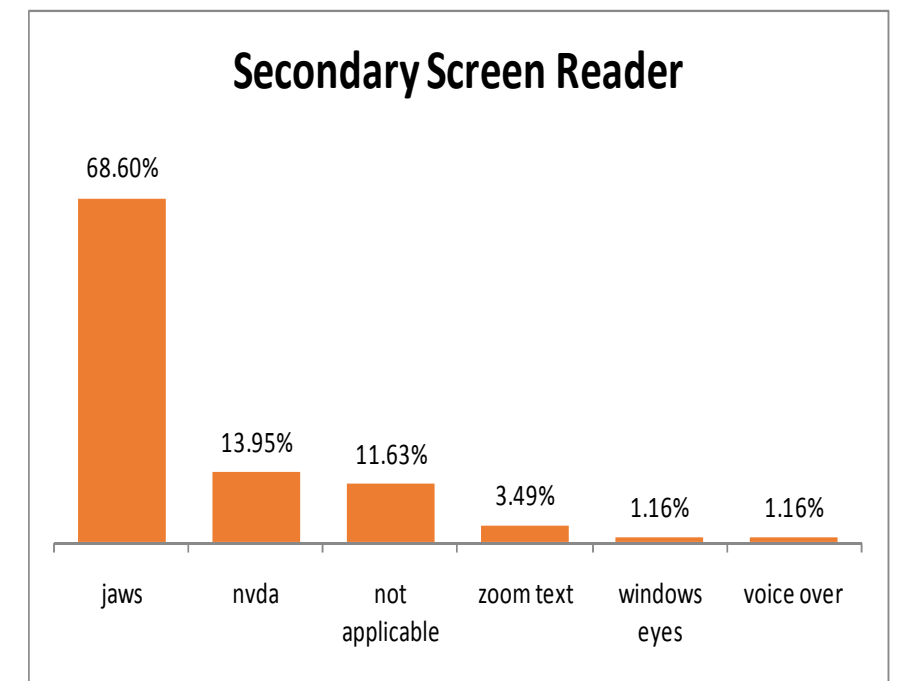

4. The study reveals that $44 \%$ of the visually-impaired students use laptop for accessing the website for accessing website, $29 \%$ of the students use mobile phones and around $25 \%$ of the students use desktop for accessing website.The comfort in using screen reader has increases the visually-impaired to use mobilephone for accessing the web content.

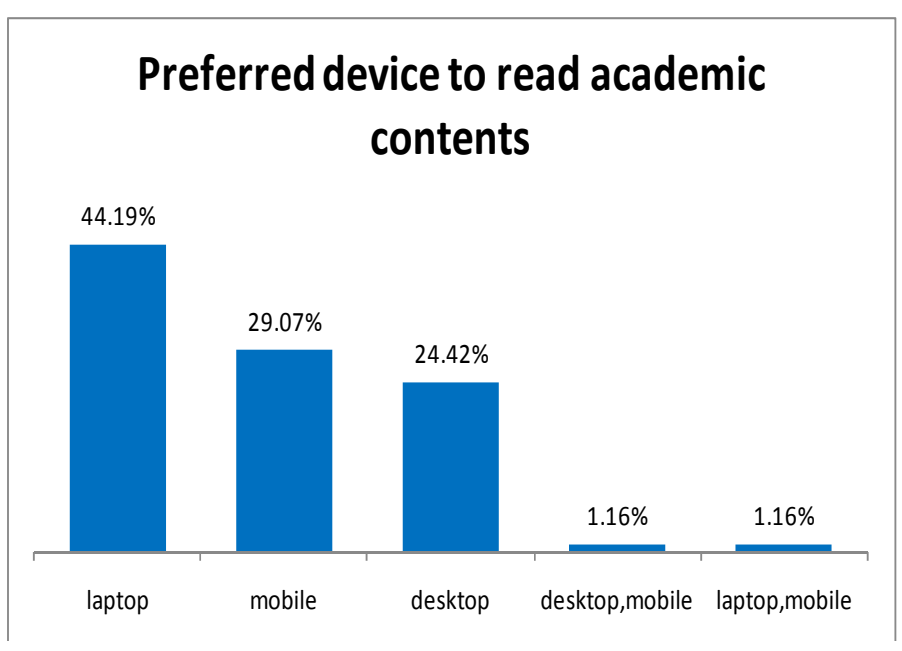

\section{CONCLUSION}

The usage of ICT-based assistive tools according to various studies clearly reveals that it helps the visually impaired students to a greater extent and these tools are categorized as adaptive tools to facilitate ease of learning among these students. It is also evident from the literature review that, the use of ICT tools proved to be more effective in imparting education for visually-impaired students. The training given to visually-impaired students will motivate them in using ICT tools for accessing the content for academic and administrative information.

\section{REFERENCES}

[1] Stefania Bocconi, Silvia Dini, Lucia Ferlino, Cristina Martinoli and Michela Ott,"“ICT educational tools and visually impaired students: different answers to different accessibility needs"

[2] Web Accessibility in Mind, (2013, Aug 28), Visual Disabilities -"How Blind People Use the Web", "Types of Low Vision" and "Types of Color-blindness" Retrieved http://webaim.org/articles/visual/blind, 
http://webaim.org/articles/visual/lowvisionand http://webaim.org/articles/visual/colorblind

[3] Matthew Butler, Leona Holloway, Kim Marriott \&CagatayGoncu, Understanding the graphical challenges faced by vision-impaired students in Australian universities, Higher Education Research \& Development, DOI:10.1080/07294360.2016.1177001, 2016

[4] Williams, P., Jamali H.R., Nicholas, D.: Using ICT with people with special education needs: what the literature tell us. Aslib Proceedings,58(4), $330 \quad-345, \quad$ (2006). http://dx.doi.org/10.1108/00012530610687704

[5] J. Jerald Inico, T. Edwin Prabakaran, Usage of ICT for Visually-impaired students in Higher Education, Mathematical Sciences International Research Journal Vol 7. Spl Issue 4, Pages 1-5 (2018).

[6] Kirakowski, J and M Corbett, (1994) SUMI: the Software Usability Measurement Inventory. Brit J Ed Technol, 23, http://sumi.uxp.ie/en/ 